\title{
POSISI DAYA SAING PERUSAHAAN TAKSI BLUE BIRD PADA ERA TEKNOLOGI DISRUPTIF
}

\author{
Victor Agustinus \\ Program Studi Magister Manajemen Universitas Tarumanagara \\ victoragustinus@yahoo.co.id
}

Masuk : 24-11-2017, revisi : 16-12-2017 diterima untuk diterbitkan : 16-12-2017

\begin{abstract}
The number of internet user in Indonesia is increasing significantly. In Indonesia, internet is not only accesed by PC but also smartphone. Therefore, new companies with new business models which utilize the internet connected smartphone is popping up nowaday. Those newcomers are serious threats to existing companies. That phenomenon is called disruptive technology. It happens to all industries including taxi services. Today, conventional taxi companies are challenged by online taxi companies. This research is aimed to identifying the competitive position of conventional taxi company in macro and micro environment.
\end{abstract}

Keywords: Disruptive Technology, Competitive Position, Taxi, Macro Environment, Micro Environment

\section{PENDAHULUAN}

Seiring dengan kemajuan teknologi, saat ini banyak perusahaan dengan model bisnis baru bermunculan. Fenomena itu mengancam perusahaan-perusahaan yang sudah lebih dulu ada dan disebut dengan teknologi disruptif. Perusahaan-perusahaan baru menawarkan nilai yang unik dan belum pernah ada sebelumnya bagi konsumen. Hal tersebut menyebabkan pangsa pasar dari perusahaan-perusahaan lama akan tergerus karena konsumen beralih ke perusahaan baru.

Salah satu jenis usaha yang terkena dampak dari era teknologi disruptif adalah usaha taksi konvensional. Saat ini bermunculan perusahaan taksi online yang mengancam perusahaan-perusahaan taksi konvensional, contohnya seperti Uber, Grab Car, dan Go Car (Go-Jek). Taksi online menawarkan berbagai nilai diantaranya adalah tarif yang lebih murah, kemudahan pemesanan, dan sebagainya. Saat ini masyarakat dapat memesan taksi online melalui smartphone dimana saja dan kapan saja. Hal tersebut tidak pernah tebayangkan pada sepuluh tahun yang lalu. Hal itu tentu saja menjadi daya tarik tersendiri bagi taksi online.

Pearson et al., menjelaskan bahwa dengan menilai posisi daya saing (competitive position) dapat mengembangkan kesempatan perusahaan untuk mendesain strategi yang mengoptimalkan peluang di lingkungannya. Kemudian dengan mengamati perkembangan kompetitor dapat membuat perusahaan meramal pertumbuhan jangka pendek dan jangka panjang serta potensi keuntungan.

Sesuai dengan uraian di atas maka penulis melakukan penelitian untuk mengetahui poisisi daya saing perusahaan taksi konvensional pada lingkungan makro dan mikro dalam era teknologi disruptif saat ini. Yang menjadi obyek penelitian dalam jurnal ini adalah PT Blue Bird Tbk. Penulis berharap jurnal ini dapat menambah pengetahuan tentang manajemen dan sebagai dasar masukan bagi perusahaan taksi konvensional yang bersangkutan untuk merumuskan strategi.

Rumusan Masalah

Melalui penulisan jurnal ini, penulis merumuskan masalah-masalah yang akan dijawab antara lain sebagai sebagai berikut:

1. Bagaimana posisi PT Blue Bird Tbk pada lingkungan makro saat ini?

2. Bagaimana posisi PT Blue Bird Tbk pada lingkungan mikro saat ini?

3. Apa kesimpulan dan saran terhadap PT Blue Bird Tbk dari hasil penelitian ini? 


\section{OBYEK PENELITIAN}

PT Blue Bird Tbk didirikan berdasarkan akta Notaris Dian Pertiwi, S.H., No. 11 tanggal 29 Maret 2001 yang telah mendapat pengesahan dari Menteri Kehakiman Republik Indonesia dalam Surat Keputusan No.C-00325-HT01.01.TH 2001, tanggal 26 April 2001. Perseroan merupakan operator taksi dengan armada terbesar di Indonesia yang dilengkapi dengan sistem argometer dan radio komunikasi. Selain itu, penggunaan sistem GPS pada armada juga memberikan rasa aman kepada para pelanggan.

Sejak memulai kegiatan komersilnya di tahun 2001 dan melakukan serangkaian restrukturisasi di tahun 2012, Perseroan telah berkembang menjadi sebuah kelompok usaha besar dengan 15 Entitas Anak yang memfokuskan diri pada kegiatan usaha di bidang transportasi penumpang dan jasa pengangkutan darat termasuk, antara lain: sewa bus, sewa kendaraan, dan jasa penyediaan taksi (reguler dan eksekutif). Selain itu, Entitas Anak menjalankan kegiatan usaha yang sifatnya menunjang kegiatan utama Perseroan tersebut, seperti perbengkelan dan perakitan.

Seiring dengan pertumbuhan usaha, Perseroan melangkah maju dengan melakukan Penawaran Umum Perdana (IPO) serta mencatatkan sahamnya di Bursa Efek Indonesia pada 5 November 2014 dengan kode saham "BIRD". Langkah IPO tersebut bertujuan untuk mendukung rencana pengembangan usaha Perseroan dalam mempertahankan posisinya sebagai pemimpin pasar di bidang jasa transportasi, khususnya layanan transportasi penumpang dan jasa pengangkutan darat.

Saat ini layanan Perseroan dapat dinikmati di wilayah Jadetabek, Bali, Bandung, Batam, Cilegon, Lombok, Manado, Medan, Padang, Pekanbaru, Palembang, Semarang, Surabaya, Yogyakarta, Cimahi, Makassar, dan Pangkal Pinang, baik di pusat bisnis maupun tujuan wisata. Dengan terus melayani jutaan penumpang setiap bulannya, Perseroan terbukti berhasil menjaga kualitas pelayanan. Strategi penempatan armada serta kemudahan mendapatkannya merupakan salah satu kunci keberhasilan Perseroan dalam meraih predikat sebagai mitra transportasi yang handal dan terpercaya.

\section{TINJAUAN PUSTAKA}

\section{Analisis PEST}

Thompson et al., (2015) menjelaskan bahwa pengaruh PEST (political, economy, social, and technological) terhadap suatu perusahaan dapat disebut juga sebagai lingkungan makro (macro environment) yang mempengaruhi perusahaan sebagaimana berikut ini:

1. Dari sisi politik (political) berupa kebijakan yang dibuat oleh pemerintah sehingga perusahaan harus mengikuti kebijakan yang berlaku meskipun kebijakan tersebut diperkirakan akan merugikan perusahaan, maka dari itu perusahaan perlu mengantisipasinya.

2. Dari sisi ekonomi (economy), perusahaan dapat memperkirakan perkembangan ekonomi dunia dan negara berdasarkan perkiraan paramater-parameter yang diumumkan oleh pemerintah seperti pertumbuhan ekonomi. Sehingga perusahaan dapat memperkirakan antara lain jumlah barang dan jasa yang harus diproduksi.

3. Dari sisi sosial (social), perusahaan mendapatkan gambaran kecenderungan yang berlaku di masyarakat misalnya tingkat pendidikan dan angka harapan hidup sehingga dengan kecenderungan ini maka perusahaan dapat mempersiapkan jasa dan produk yang sesuai.

4. Dari sisi teknologi (technological) dengan adanya temuan teknologi baru yang mempunyai kapasitas dan kecepatan yang lebih baik serta waktu munculnya teknologi tersebut akan semakin cepat sehingga menuntut perusahaan harus berhati-hati dalam menerapkan teknologi baru. 


\section{Analisis Lima Kekuatan Porter}

Untuk menganalisis lingkungan mikro (micro environment) atau dikenal dengan lingkungan industri dapat menggunakan analisis lima kekuatan yang diperkenalkan oleh Michael Porter. Menurut Porter (1980), lima kekuatan tersebut adalah sebagai berikut:

1. Persaingan antara pesaing dalam industri yang sama (rivalry among competition). Persaingan dalam bidang ini yang merupakan inti dari persaingan karena masing-masing perusahaan berusaha untuk menggunguli perusahaan pesaingnya. Pada aspek ini akan berpengaruh jumlah dan kesetaraan pesaing dan juga tingkat pertumbuhan industri.

2. Ancaman masuknya pendatang baru (threat of entry). Suatu industri yang menawarkan keuntungan (return) yang tinggi akan mengundang perusahaan baru atau produk baru untuk masuk kedalam industri tersebut. Sehingga secara makro akan membuat persaingan menjadi lebih ketat dan akan berakibat pada penurunan keuntungan pada semua perusahaan di industri tersebut.

3. Ancaman barang substitusi (threat of substitutions). Produk subsitusi merupakan barang atau jasa yang dapat mengantikan produk sejenis, misalnya taksi reguler dapat digantikan oleh kendaraan umum lainnya yang tidak sejenis. Tingkat substitusinya dipengaruh oleh faktor antara lain harga dan biaya pengalihan.

4. Daya tawar penjual (bargaining power of suppliers). Dipengaruhi faktor jumlah pemasok dan barang atau jasa yang disediakan oleh pemasok. Makin sedikit pemasok maka makin kuat ancamannya terhadap perusahaan.

5. Daya tawar pembeli (bargaining power of buyers). Faktor ini merupakan hal penting karena kepuasan pelanggan dalam membeli merupakan kunci sukses suatu perusahaan. Adapun faktor yang mempengaruhinya adalah pangsa pembeli yang besar, banyaknya produk substitusi dan biaya pengalihan produk yang kecil.

\section{METODOLOGI PENELITIAN}

Metodologi dalam penelitian ini mengunakan alat-alat analisa yang terdapat dalam bukubuku rujukan yaitu PEST dan Porter's Five Forces. Kemudian untuk mendukung analisis digunakan data-data yang bersumber dari hasil pengamatan penulis. Berikut ini merupakan kerangka pemikiran dari penelitian ini.

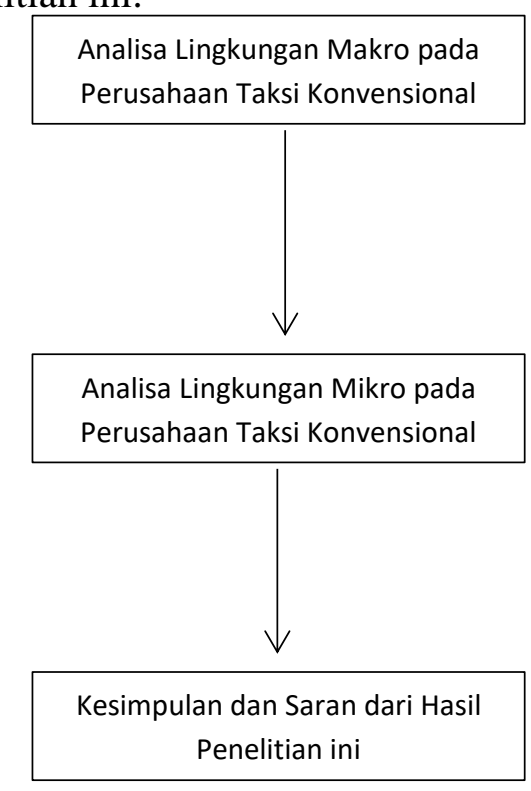


ANALISIS DAN PEMBAHASAN

\section{Lingkungan Makro}

Seperti yang telah disebutkan pada bagian sebelumnya, lingkungan makro dari PT Blue Bird Tbk dipengaruhi oleh empat faktor yaitu politik, ekonomi, sosial, dan teknologi (PEST). Berikut ini merupakan hasil pengamatan dari kondisi keempat faktor tersebut di Indonesia.

1. Politik

Indeks Demokrasi Indonesia (IDI) 2016 mencapai angka 70,09 dalam skala 0 sampai 100. Angka ini mengalami penurunan dibandingkan dengan angka IDI 2015 yang sebesar 72,82. Capaian kinerja demokrasi Indonesia tersebut masih berada pada kategori "sedang". Klasifikasi tingkat demokrasi dikelompokkan menjadi tiga kategori: yakni "baik" (indeks > 80), "sedang" (indeks $60-80$ ), dan "buruk" (indeks < 60). Perubahan dari 2015-2016 dipengaruhi tiga aspek demokrasi yakni (1) Kebebasan Sipil yang turun 3,85 poin (dari 80,30 menjadi 76,45), (2) Hak-Hak Politik yang turun 0,52 poin (dari 70,63 menjadi 70,11), dan (3) Lembaga-lembaga Demokrasi yang turun 4,82 poin (dari 66,87 menjadi 62,05) (Laporan Bulanan Data Sosial Ekonomi November 2017, Badan Pusat Statistik, 2017).

2. Ekonomi

Hasil pendaftaran (Listing) Sensus Ekonomi 2016 (SE2016) tercatat sebanyak 26,71 juta usaha/perusahaan, meningkat 17,51 persen dibandingkan dengan hasil Sensus Ekonomi 2006 (SE06) yang berjumlah 22,73 juta usaha/perusahaan. Bila dibedakan menurut skala usaha, 26,26 juta usaha/perusahaan (98,33 persen) berskala Usaha Mikro Kecil (UMK) dan 0,45 juta usaha/perusahaan (1,67 persen) berskala Usaha Menengah Besar (UMB). Jumlah tenaga kerja hasil SE2016 tercatat sebanyak 70,32 juta, yang didominasi lapangan usaha perdagangan besar dan eceran sebanyak 22,37 juta tenaga kerja atau 31,81 persen dari tenaga kerja yang ada di Indonesia (Badan Pusat Statistik, 2017).

3. Sosial

Pembangunan manusia di Indonesia terus mengalami kemajuan yang ditandai dengan terus meningkatnya Indeks Pembangunan Manusia (IPM). Pada tahun 2016, IPM Indonesia telah mencapai 70,18, memasuki IPM kategori "Tinggi". Angka ini meningkat sebesar 0,63 poin atau tumbuh sebesar 0,91 persen dibandingkan dengan IPM Indonesia pada tahun 2015 yang sebesar 69,55. Kemudian Indeks Perilaku Anti Korupsi (IPAK) Indonesia 2017 sebesar 3,71 pada skala 0 sampai 5. Angka ini lebih tinggi dibandingkan capaian tahun 2015 sebesar 3,59 (Badan Pusat Statistik, 2017).

4. Teknologi

Jumlah pelanggan telepon seluler di Indonesia pada tahun 2015 sebanyak 338.9483430, jumlah tersebut naik dari tahun sebelumnya yaitu 325.582.891 (Kementerian Komunikasi dan Informatika, Publikasi Statistik Indonesia, 2016). Data WeAreSocial Digital 2017 Global Overview memperlihatkan penetrasi mobile broadband di Indonesia sebesar 65\% (Walfajri, M., 7 November, 2017).

Dari hasil pengamatan lingkungan makro di atas, faktor politik cukup berpengaruh terhadap PT Blue Bird Tbk, karena dengan membaiknya kodisi Indeks Demokrasi Indonesia (IDI) maka aspirasi pengusaha taksi dapat tersampaikan. Oleh karena hal tersebut, saat ini pemerintah menentapkan syarat yang lebih ketat terhadap taksi online bahkan di berberapa tempat ada yang melarangnya sama sekali. Faktor ekonomi juga cukup berpengaruh dimana terjadi peningkatan selama sepuluh tahun terakhir yang merupakan peluang bagi PT Blue Bird Tbk untuk meningkatkan pendapatan. Kemudian faktor sosial, pengaruhnya cukup besar terhadap PT Blue Bird Tbk. Dengan meningkatnya Indeks Pembangunan Manusia (IPM) di Indonesia maka tingkat pendidikan, angka harapan hidup, dan sebagainya juga meningkat. Dan hal tersebut menguntungkan PT Blue Bird Tbk, misalnya perusahaan akan semakin mudah dalam merekrut tenaga kerja profesional, melakukan pengembangan layanan, dan sebagainya. Faktor yang paling berpengaruh terhadap PT Blue Bird Tbk adalah teknologi. Saat ini jumlah 
pengguna mobile broadband di Indonesia mencapai $65 \%$ dan saat ini masyarakat dapat memanfaatkan layanan taksi online melalui smartphone. Namun untuk hal tersebut, PT Blue Bird Tbk telah beradaptasi dengan meluncurkan aplikasi My Blue Bird yang sistemnya sama seperti taksi online. Berikut ini merupakan tabel yang menunjukkan kesimpulan pengaruh PEST terhadap PT Blue Bird Tbk.

\section{Lingkungan Mikro}

\begin{tabular}{|l|l|l|}
\hline No. & Faktor PEST & Pengaruh \\
\hline 1 & Politik & Medium \\
\hline 2 & Ekonomi & Medium \\
\hline 3 & Sosial & Medium \\
\hline 4 & Teknologi & High \\
\hline
\end{tabular}

Teknik yang digunakan untuk menganalisis lingkungan mikro pada penelitian ini adalah analisis lima kekuatan Porter. Berikut ini merupakan pengaruh lima kekuatan Porter terhadap PT Blue Bird Tbk.

1. Rivalry among Competition

Jumlah taksi bandara yang beroperasi tahun 2015 adalah sebanyak 4.420 menurun dari 4.490 pada tahun sebelumnya. Kemudian jumlah perusahaan taksi bandara pada tahun 2015 adalah sebanyak 10 perusahaan menurun dari jumlah 13 pada tahun sebelumnya (Statistik Perhubungan Tahun 2015 Jilid 1, Kemenhub, 2015). Pada periode 2013-2014, taksi yang beroperasi di Jakarta ada 25.500 unit. Namun tahun 2017 yang beroperasi kurang lebih 9.000 unit saja. Dan dari 35 operator taksi pada tahun 2013-2014, pada tahun 2017 hanya ada 4 operator taksi (Septian, D., Maret, 2017).

2. Threat of Entry

Walaupun terjadi penurunan terhadap jumlah perusahaan dan jumlah armada taksi di Indonesia namun perusahaan-perusahaan taksi konvensional terus berinovasi untuk menghadirkan layanan baru. Saat ini mobil jenis MPV (Multi Purpose Vehicle) yang dapat memuat lebih banyak penumpang daripada mobil jenis sedan. Dan tarif yang dikenakan pada taksi MPV juga sama dengan taksi sedan sehingga menjadi daya tarik tersendiri. Salah satu perusahaan taksi yang menggunakan MPV adalah Gamya.

3. Threat of Subtitutions

Berdasarkan data pada 2016, pasar taksi di Indonesia sudah dikuasai oleh pelaku startup bidang ridesharing seperti Go-Jek dan Grab sebesar 60\% (Walfajri, M., 7 November, 2017). Perusahaan-perusahaan startup tersebut berbeda dengan perusahaan taksi konvensional. Mereka tidak memiliki armada sendiri namun menjalin kemitraan dengan pemilik mobil pribadi untuk disewakan kepada penumpang.

4. Bargaining Power of Suppliers

Sejak tanggal 21 Maret 2017, Pertamina sebagai pemasok utama BBM (Bahan Bakar Minyak) belum mengumumkan kenaikan harga kembali. Kemudian industri otomotif yang menjadi pemasok armada taksi mengalami peningkatan penjualan. Hingga Juni 2017 telah mencapai 533.537 unit atau meningkat 0,3 persen pada periode di tahun sebelumnya (Luthfi Andika, M., Agustus, 2017). Mitsubishi Indonesia mengeluarkan model terbaru di kelas MPV dengan harga yang kompetitif yaitu Expander. Selain itu muncul perusahaan otomotif baru yaitu Wuling Indonesia.

5. Bargaining Power of Buyers

Indeks Tendensi Konsumen (ITK) pada triwulan III-2017 sebesar 109,42. Hal ini menunjukan kondisi ekonomi konsumen meningkat dibandingkan triwulan sebelumnya. Jumlah kunjungan wisatawan mancanegara atau wisman selama JanuariSeptember 2017 mencapai 10,46 juta kunjungan atau naik 25,05 persen dibandingkan dengan jumlah kunjungan wisman pada periode yang sama tahun 2016. (Badan Pusat Statistik, 2017). 
Bisnis taksi konvensional saat ini mengalami penurunan drastis dimana banyak perusahaan yang tutup dan jumlah armada taksi yang beroperasi yang berkurang banyak. Hal itu juga terjadi pada PT Blue Bird Tbk dimana jumlah armada taksi reguler pada tahun 2016 sebanyak 24.873 menurun dari 26.719 pada tahun 2015 (Annual Report 2016, PT Blue Bird Tbk, 2017). Kemunculan pendatang baru berupa taksi MPV bukanlah ancaman besar bagi PT Blue Bird Tbk, sebab perusahaan taksi tersebut sudah memiliki armada sejenis sebelumnya. Sebaliknya ancaman dari subtitusi dapat dikatakan besar dampaknya bagi PT Blue Bird Tbk, seperti yang telah disebutkan diatas bahwa taksi online sudah menguasai $60 \%$ pasar taksi di Indonesia. Untuk mengatasi hal tersebut PT Blue Bird telah melakukan kerjasama dengan taksi online agar taksi Blue Bird dapat dipesan melalui aplikasi taksi online. Ketersedian BBM dan mobil dari pemasok relatif stabil dari segi harga dan jumlah untuk PT Blue Bird Tbk. Kemudian walaupun kondisi ekonomi konsumen dan jumlah wisatawan meningkat namun pendapatan operasional taksi reguler PT Blue Bird Tbk menurun dari 4,7 triliun menjadi 4 triliun rupiah pada tahun 2016 (PT Blue Bird Tbk, 2017). Berikut ini merupakan tabel yang menunjukkan kesimpulan pengaruh lima kekuatan Porter terhadap PT Blue Bird Tbk.

\begin{tabular}{|l|l|l|}
\hline No. & Porter's Five Powers & Pengaruh \\
\hline 1 & Rivalry among Competition & Medium \\
\hline 2 & Threat of Entry & Medium \\
\hline 3 & Threat of Subtitutions & High \\
\hline 4 & Bargaining Power of Suppliers & Low \\
\hline 5 & Bargaining Power of Buyers & Low \\
\hline
\end{tabular}

\section{KESIMPULAN DAN SARAN}

Faktor teknologi pada lingkungan makro sangat berpengaruh terhadap PT Blue Bird Tbk. Hal tersebut juga terjadi pada lingkungan mikro dimana muncul perusahaan-perusahaan startup yang mengandalkan kemajuan teknologi dan merupakan ancaman besar pada PT Blue Bird Tbk. Maka dari itu PT Blue Bird Tbk banyak melakukan perubahan ketika memasuki era tekonologi disruptif ini. Perubahan itu seperti menyediakan aplikasi pemesanan taksi Blue Bird online dan menggunakan armada taksi MPV. Hal tersebut dapat dipahami sebagai upaya perusahaan agar dapat terus bertahan. Namun PT Blue Bird Tbk mengalami penurunan pendapatan dan jumlah aramada pada bisnis taksi reguler yang menandakan bahwa upaya perusahaan masih belum cukup untuk dapat terus bertahan pada era teknologi disruptif ini.

PT Blue Bird Tbk dapat melakukan diversifikasi bisnis untuk mengurangi ketergantungan pada bisnis taksi reguler. Misalnya dengan membuka bisnis baru yang lebih menguntungkan yang tak terkait dengan taksi. Saat ini PT Blue Bird Tbk telah melakukan kerjasama dengan taksi online agar saling menguntungkan, hal tersebut dapat ditingkatkan. Jumlah armada taksi PT Blue Bird Tbk sebaiknya disesuaikan dengan proyeksi pasar agar tidak membebani keuangan perusahaan.

\section{DAFTAR PUSTAKA}

Pearson, J., \& Robinson, R. (2015). Strategic Management: Planning for Domestic and Global Competition (14 ${ }^{\text {th }}$ ed.). New York, USA: McGraw-Hill.

Porter, M. E. (1980). Competitive Strategy: Techniques for Analyzing Industries and Competitors. New York, UA: The Free Press.

Thompson, A., Peteraf, M., Gamble, J., \& Strickland III, A. J. (2015). Crafting and Executing Strategy: The Quest for Competitive Advantag: Concepts and Cases (20 ${ }^{\text {th }}$ ed.). New York, USA: McGraw-Hill.

Badan Pusat Statistik. (2016). Jumlah Pelanggan Telepon Indonesia. Retrieved November 5, 2017, from BPS Website http://www.bps.go.id/linkTabelStatis/view/id/1844

Badan Pusat Statistik. (2017). Laporan Bulanan Data Sosial Ekonomi November 2017. Retrieved November 5, 2017, from BPS Website http://www.bps.go.id/publikasi/view 
Departemen Perhubungan. (2016). Buku Statistik Perhubungan (Jilid 1). Retrieved November 5, 2017, from Dephub Website http://ppid.dephub.go.id/files/buku-statistikperhubungan-jilid-1-2015.pdf

Detik. (2017). Rapor Industri Otomotif di Mata Gaikindo. Retrieved November 7, 2017, from Detik Website http://www.detik.com/oto/event/3593550/rapor-industri-otomotif-dimata-gaikindo

Kontan. (2017). Prospek e-commerce Indonesia Menggiurkan. Retrieved November 7, 2017, from Kontan Website http://www.kontan.co.id/news/prospek-e-commerce-Indonesiamenggiurkan

Liputan 6. (2017). Kalah dengan Online, Operator Taksi di Jakarta Tinggal 4. Retrieved November 7, 2017, from Liputan 6 Website http://www.liputan6.com/bisnis/read/2898875/kalah-dengan-online-operator-taksi-dijakarta-tinggal-4-pemain

PT Blue Bird Tbk. (2017). Laporan Tahunan 2016. Retrieved November 5, 2017, from PT Blue Bird Tbk Website http://www.bluebirdgroup.com/id/investor-relations/laporantahunan 